CUBO A Mathematical Journal

Vol.14, $N^{\underline{O}}$ 01, (55-79). March 2012

\title{
Bounded and Periodic Solutions of Integral Equations
}

\author{
T. A. Burton \\ Northwest Research Institute \\ 732 Caroline Street, Port Angeles, WA 98362 \\ email: taburton@olypen.com \\ and \\ BO ZHANG \\ Department of Mathematics and Computer Science \\ Fayetteville State University \\ Fayetteville, NC 28301 \\ email: bzhang@uncfsu.edu
}

\begin{abstract}
In this paper we introduce a new method for obtaining boundedness of solutions of integral equations. From the integral equation we form an integrodifferential equation by computing $x^{\prime}+k x$ to which we apply a Liapunov functional. This can be far more effective than the usual technique of differentiating the equation. The qualitative properties derived from that equation are then transferred to a majorizing function for the integral equation. Schaefer's fixed point theorem is used to conclude that there is a periodic solution. Three kinds of integral equations are studied and they are shown to be related through two examples.
\end{abstract}

\section{RESUMEN}

En este artículo presentamos un nuevo método para obtener acotación de soluciones de ecuaciones integrales. A partir de la ecuación integral, formamos una ecuación íntegro- 
diferencial calculando $x^{\prime}+k x$ mediante la aplicación de un funcional de Liapunov. Ello puede resultar bastante más efectivo que la técnica usual de diferenciación de la ecuación. Las propiedades cualitativas derivadas de la ecuación son entonces transferidas a la función mayorante para la ecuación integral. El teorema del punto fijo de Schaefer es usado para concluir que hay una solución periódica. Se estudia tres tipos de ecuaciones integrales y se muestra que ellas están relacionadas a través de dos ejemplos.

Keywords and Phrases: Integral Equations, Boundedness, Periodic Solutions, Liapunov Functions.

2010 AMS Mathematics Subject Classification: 45D05, 45D20, 45M15.

\section{Introduction}

In this paper we consider several nonlinear scalar integral equations of the form

$$
x(t)=a(t)-\int_{\alpha(t)}^{t} C(t, s) g(x(s)) d s
$$

where $\alpha(t)$ may be zero, $-\infty$, or $t-h$ for some constant $h>0$. In each of the problems the kernel need not be convex, but the assumption is that there is a constant $k>0$ with

$$
\mathrm{D}(\mathrm{t}, \mathrm{s}):=\mathrm{C}_{\mathrm{t}}(\mathrm{t}, \mathrm{s})+\mathrm{kC}(\mathrm{t}, \mathrm{s})
$$

convex. For existence theory see [3], [5], [15].

In 1928 Volterra [17] noted that many physical problems were being modeled by integral and integrodifferential equations with convex kernels. Such kernels are natural representations of fading memory. Today we see such models in problems in biology, neural networks, viscoelasticity, nuclear reactors, and many other places. See [4]-[8],[11], [14], [17], [19]-[20] for work on integral equations with convex kernels.

In addition to the natural fading memory, by 1963 there arose another good reason to try to formulate problems with such kernels. In that same paper Volterra had suggested that there might be constructed a Liapunov functional which would yield very precise qualitative properties of solutions, and that it would admit arbitrarily large kernels. This is in marked contrast to so much of the theory which leaves the investigator strapped with Draconian conditions such as $\int_{0}^{t}|C(t, s)| d s \leq \gamma<1$. In 1963 Levin [10] followed Volterra's suggestion and constructed a Liapunov functional for the convolution case (see also [13]) and in 1968 [12] he constructed (1.5) below for

$$
x^{\prime}(t)=-\int_{0}^{t} C(t, s) g(x(s)) d s, x g(x)>0 \text { if } x \neq 0
$$

where $\mathrm{C}(\mathrm{t}, \mathrm{s})$ is convex:

$$
C(t, s) \geq 0, C_{s}(t, s) \geq 0, C_{s t}(t, s) \leq 0, C_{t}(t, s) \leq 0
$$


His functional has the form

$$
V(t)=2 \int_{0}^{x} g(s) d s+\int_{0}^{t} C_{s}(t, s)\left(\int_{s}^{t} g(x(u)) d u\right)^{2} d s+C(t, 0)\left(\int_{0}^{t} g(x(u)) d u\right)^{2}
$$

with derivative along solutions of (1.3) satisfying

$$
V^{\prime}(t)=\int_{0}^{t} C_{s t}(t, s)\left(\int_{s}^{t} g(x(u)) d u\right)^{2} d s+C_{t}(t, 0)\left(\int_{0}^{t} g(x(u)) d u\right)^{2} \leq 0
$$

Much work followed in that same vein. See Zhang [19]-[20] for systems.

In 1992 (see [1] and [2]) we constructed parallel Liapunov functions for (1.1), taking into account the various forms of $\alpha(t)$. Here, also, one finds much work following in the same vein. Long before the 1992 work appeared, investigators had differentiated (1.1) to obtain an integrodifferential equation to which they could apply Liapunov's direct method. Miller [15] formally starts his Chapter 6 with such a presentation. Fruitful as that approach has been, it also has significant difficulties. A more refined approach was introduced in Chapter 9 of [5] and that has been used with success in a number of subsequent papers, each of which features a new advantage to the technique.

In each case, the idea is to form $x^{\prime}+k x$ from (1.1). For $\alpha=0$ we have

$$
x^{\prime}+k x=a^{\prime}(t)+k a(t)-C(t, t) g(x(t))-\int_{0}^{t} D(t, s) g(x(s)) d s
$$

with D defined in (1.2). There are six important observations.

(i) $x^{\prime}+k x$ is a uniformly asymptotically stable operator for $k>0$.

(ii) If $C(t, t) \geq 0$ and if $x g(x)>0$ for $x \neq 0$, then $x^{\prime}+k x+C(t, t) g(x)$ is an operator of the same, but stronger, type.

(iii) If $C$ and $C_{t}$ differ in sign then $D(t, s)$ is smaller than the larger of the two terms. (See [5] and [9].)

(iv) Under general conditions if $C$ is convex and $k$ is large then $D$ is convex, while the kernel for $\chi^{\prime}$ alone has lost its convexity. (See [6].)

(v) If $\mathrm{C}(\mathrm{t}, \mathrm{s})$ is not convex while $\mathrm{D}(\mathrm{t}, \mathrm{s})$ is, then the combined equation (1.7) is the right form to apply Liapunov functionals. (See Example 3.1.)

(vi) The utility of a Liapunov functional often depends on the separation of its derivative into a difference, say $|p(t)|-|h(x)|$. Using $C$ alone, that can require strong conditions on $g$, but when using $\mathrm{D}$ there is a natural separation [6].

To be fair, one should ask if something has been lost. It has, and it introduces a new problem. The Liapunov functional which we constructed in 1992 for (1.1) works with a more general $\mathrm{g}(\mathrm{t}, \mathrm{x})$, but the Levin Liapunov functional which we will use on the $x^{\prime}+k x$ equation needs $g(x)$. It would be so interesting to extend Levin's Liapunov functional to $g(t, x)$ for (1.3). 
That is the background and we now move along with some new problems. The first of which is to use a combination of the two Liapunov functionals and the systems (1.1) and (1.7). First we prove the existence of a periodic solution when $\alpha=\infty$. We then study the case of $\alpha=0$ proving boundedness properties. Finally, we take $\alpha=\mathrm{t}-\mathrm{h}$ and prove both boundedness and periodicity.

Let $R^{+}=[0, \infty), R=(-\infty, \infty)$, and $C(X, Y)$ denote the space of continuous functions $\phi: X \rightarrow$ $\mathrm{Y}$. We also denote by $\left(\mathrm{P}_{\mathrm{T}},\|\cdot\|\right)$ the Banach space of continuous $\mathrm{T}$-periodic functions $\phi: \mathrm{R} \rightarrow \mathrm{R}$ with the supremum norm.

For the existence of periodic solutions, we apply Schaefer's fixed point theorem (see below) with $F(x)$ being the right-hand side of (1.1) so that if $F$ has a fixed point, then this fixed point is a periodic solution of (1.1).

Theorem 1.1 (Schaefer [16]). Let $(\mathrm{P},\|\cdot\|)$ be a normed space, $\mathrm{F}$ a continuous mapping of $\mathrm{P}$ into $\mathrm{P}$ which is compact on each bounded subset of $\mathrm{P}$. Then either

(i) the equation $\phi=\lambda \mathrm{F} \phi$ has a solution for $\lambda=1$, or

(ii) the set of all such solutions $\phi$, for $0<\lambda<1$, is unbounded.

\section{Boundedness and Periodicity}

We consider the equation

$$
x(t)=\lambda\left[a(t)-\int_{-\infty}^{t} C(t, s) g(x(s)) d s\right], 0 \leq \lambda \leq 1
$$

where $a: R \rightarrow R, C: R \times R \rightarrow R, g: R \rightarrow R$ are all continuous. Suppose that there is a positive constant $\mathrm{k}$ so that

$$
\mathrm{D}(\mathrm{t}, \mathrm{s}):=\mathrm{C}_{\mathrm{t}}(\mathrm{t}, \mathrm{s})+\mathrm{kC}(\mathrm{t}, \mathrm{s}) \text { is convex. }
$$

We first want to show that there exists a constant $\gamma>0$ such that $|x(t)| \leq \gamma$ whenever $x$ is a T-periodic solution of (2.1) for all $0 \leq \lambda \leq 1$. We then show the existence of a T-periodic solution of (2.1) for $\lambda=1$ by applying Schaefer's fixed point theorem. Our main assumptions are that there is a $T>0$ and $\mathrm{J}>0$ such that

$$
\mathrm{a}(\mathrm{t}+\mathrm{T})=\mathrm{a}(\mathrm{t}), \quad \mathrm{C}(\mathrm{t}+\mathrm{T}, \mathrm{s}+\mathrm{T})=\mathrm{C}(\mathrm{t}, \mathrm{s})
$$

for all $s \leq t$ with $a^{\prime}$ continuous and

$$
\sup _{0 \leq t \leq T} \int_{-\infty}^{t} D(t, s)(t-s) d s \leq J
$$

and that D satisfies

$$
D(t, s) \geq 0, \quad D_{s}(t, s) \geq 0, \quad D_{s t}(t, s) \leq 0
$$


We differentiate (2.1) and form

$$
x^{\prime}+k x=\lambda\left[a^{\prime}+k a-C(t, t) g(x)-\int_{-\infty}^{t} D(t, s) g(x(s)) d s\right] .
$$

Now, we define the Liapunov functional

$$
V(t)=2 \int_{0}^{x(t)} g(s) d s+\lambda \int_{-\infty}^{t} D_{s}(t, s)\left(\int_{s}^{t} g(x(v)) d v\right)^{2} d s
$$

for $x \in\left(\mathrm{P}_{\mathrm{T}},\|\cdot\|\right)$.

Theorem 2.1. Suppose that (2.3), (2.4), (2.5), (2.9) and (2.10) hold. If $x(\mathrm{t})$ is a T-periodic solution of (2.1), then the derivative of $\mathrm{V}$ along that solution satisfies

$$
V^{\prime}(t) \leq 2 \lambda g(x)\left[a^{\prime}(t)+k a(t)\right]-2 g(x)[k x+\lambda C(t, t) g(x)] .
$$

If there is an $\mathrm{L}>0$ with

$$
x g(x) \geq 0 \text { for }|x| \geq \mathrm{L}
$$

and if, in addition, there is $a \mu>0$ with

$$
g(x)[k x+C(t, t) g(x)] \geq \mu g^{2}(x)
$$

for $|x| \geq \mathrm{L}$, then there is an $\mathrm{M}>0$ with

$$
V^{\prime}(t) \leq-|g(x)|+M
$$

Proof. We first define some constants to simplify notation. Integrating by parts, we obtain

$$
\begin{aligned}
\int_{b}^{t} D_{s}(t, s)(t-s)^{2} d s & =\left.D(t, s)(t-s)^{2}\right|_{b} ^{t}+2 \int_{b}^{t} D(t, s)(t-s) d s \\
& =-D(t, b)(t-b)^{2}+2 \int_{b}^{t} D(t, s)(t-s) d s
\end{aligned}
$$

for each $b<t$. Since $D(t, s) \geq 0$ and $D_{s}(t, s) \geq 0$, letting $b \rightarrow-\infty$, we see that

$$
\int_{-\infty}^{t} D_{s}(t, s)(t-s)^{2} d s+\lim _{s \rightarrow-\infty} D(t, s)(t-s)^{2}=2 \int_{-\infty}^{t} D(t, s)(t-s) d s \leq 2 J .
$$

Observe also that

$$
D(t, b)(t-b)^{2} \leq 2 \int_{b}^{t} D(t, s)(t-s) d s \leq 2 J
$$


for all $\mathrm{b} \leq \mathrm{t}$. This then implies that $\mathrm{D}(\mathrm{t}, \mathrm{s})(\mathrm{t}-\mathrm{s}) \leq 2 \mathrm{~J} /(\mathrm{t}-\mathrm{s})$ for all $s<\mathrm{t}$, and so we arrive at

$$
\lim _{s \rightarrow-\infty}(t-s) D(t, s)=0 \text { for fixed } t
$$

and obtain

$$
\int_{-\infty}^{t} D_{s}(t, s) d s=\lim _{b \rightarrow-\infty}[D(t, t)-D(t, b)] \leq \sup _{0 \leq t \leq T} D(t, t)=: B .
$$

Now let $x$ be a T-periodic solution of (2.1) and $V(t)$ be defined in (2.7). It follows from (2.12) that $\mathrm{V}(\mathrm{t})$ is well-defined and $\mathrm{T}$-periodic. We then find

$$
\begin{aligned}
V^{\prime}(t)= & 2 g(x) x^{\prime}(t)+\lambda \int_{-\infty}^{t} D_{s t}(t, s)\left(\int_{s}^{t} g(x(v)) d v\right)^{2} d s \\
& +2 \lambda g(x) \int_{-\infty}^{t} D_{s}(t, s) \int_{s}^{t} g(x(v)) d v d s .
\end{aligned}
$$

Integration of the last term by parts and use of (2.13) in the lower limit for that periodic solution yields

$$
\int_{-\infty}^{t} D_{s}(t, s) \int_{s}^{t} g(x(v)) d v d s=\int_{-\infty}^{t} D(t, s) g(x(s)) d s .
$$

Since $D_{s t}(t, s) \leq 0$, the second term of $V^{\prime}$ is not positive, and thus, if we use (2.6), we obtain

$$
\begin{aligned}
V^{\prime}(t) \leq & 2 g(x)\left[-k x+\lambda\left(a^{\prime}+k a\right)-\lambda C(t, t) g(x)-\lambda \int_{-\infty}^{t} D(t, s) g(x(s)) d s\right] \\
& +2 \lambda g(x) \int_{-\infty}^{t} D(t, s) g(x(s)) d s \\
= & 2 \lambda g(x)\left[a^{\prime}(t)+k a(t)\right]-2 g(x)[k x+\lambda C(t, t) g(x)]
\end{aligned}
$$

verifying (2.8).

Next we choose $N>1$ so large that $-\mu(N-1)<C_{*}=\min \{C(t, t): 0 \leq t \leq T\}$, where $\mu>0$ 
is defined in (2.10). If $|x| \geq \mathrm{L}$, then $x g(x) \geq 0$, and by (2.10), we obtain for $|x(t)| \geq L$ that

$$
\begin{aligned}
V^{\prime}(t) \leq & 2 \lambda|g(x)|\left[\left\|a^{\prime}\right\|+k\|a\|\right]-2 g(x)[k x+\lambda C(t, t) g(x)] \\
\leq & 2|g(x)|\left[\left\|a^{\prime}\right\|+k\|a\|\right]-2 k \frac{1}{N} x g(x) \\
& -2 \lambda\left(1-\frac{1}{N}\right) g(x)[k x+C(t, t) g(x)]-2 \lambda \frac{1}{N} C(t, t) g^{2}(x) \\
\leq & 2|g(x)|\left[\left\|a^{\prime}\right\|+k\|a\|\right]-2 k \frac{1}{N} x g(x) \\
& -2 \lambda\left(1-\frac{1}{N}\right) \mu g^{2}(x)-2 \lambda \frac{1}{N} C(t, t) g^{2}(x) \\
\leq & -2|g(x)|\left[\frac{1}{N} k|x|-\left(\left\|a^{\prime}\right\|+k\|a\|\right)\right] .
\end{aligned}
$$

We may assume that $L \geq N\left(\left\|a^{\prime}\right\|+k\|a\|+1\right) / k$. Thus, if $|x(t)| \geq L$, then $V^{\prime}(t) \leq-|g(x(t))|$. It is clear that $V^{\prime}(t) \leq M$ for $0 \leq|x(t)| \leq L$, where

$$
M=2 g_{L}\left[\left\|a^{\prime}\right\|+k\|a\|\right]+2 g_{L}\left[k L+C^{*} g_{L}\right]
$$

with $g_{\mathrm{L}}=\sup \{|\mathrm{g}(\mathrm{x})|:|\mathrm{x}| \leq \mathrm{L}\}$ and $\mathrm{C}^{*}=\sup \{|\mathrm{C}(\mathrm{t}, \mathrm{t})|: 0 \leq \mathrm{t} \leq \mathrm{T}\}$, and hence,

$$
V^{\prime}(t) \leq-|g(x(t))|+M
$$

for all $t \geq 0$. This completes the proof.

To establish an a priori bound for all possible T-periodic solutions of (2.1), we assume that

$$
\lim _{s \rightarrow-\infty}(t-s) C(t, s)=0 \text { and } \int_{-\infty}^{t}\left|C_{s}(t, s)\right|(t-s) d s \leq J_{1}
$$

for $\mathrm{J}_{1}>0$.

Theorem 2.2. Suppose that (2.3)-(2.5), (2.9)-(2.10) and (2.15) hold. Then there exists a constant $\gamma>0$ such that $\|\mathrm{x}\|<\gamma$ whenever $\mathrm{x}$ is a T-periodic solution of (2.1).

Proof. Let $x$ be a T-periodic solution of (2.1) and $V(t)$ be defined in (2.7). Then (2.11) holds. Since $V(t)$ is $T$-periodic, $V(t)$ has a global maximum at $q \in[0, T]$ and, hence, at $t_{n}=q+n T$. So for $s \leq t_{n}$, we have

$$
0 \leq \mathrm{V}\left(\mathrm{t}_{\mathrm{n}}\right)-\mathrm{V}(\mathrm{s}) \leq-\int_{\mathrm{s}}^{\mathrm{t}_{\mathrm{n}}}|\mathrm{g}(x(v))| \mathrm{d} v+\mathrm{M}\left(\mathrm{t}_{\mathrm{n}}-\mathrm{s}\right)
$$

and so

$$
\int_{s}^{t_{n}}|g(x(v))| d v \leq M\left(t_{n}-s\right)
$$


Then $(x(t)-\lambda a(t))^{2}$ has a global maximum at $h_{n}:=t_{n}+p$, where $0 \leq p \leq T$, and for $s \leq h_{n}$ we have

$$
\int_{s}^{h_{n}}|g(x(v))| d v \leq \int_{s}^{t_{n+1}}|g(x(v))| d v \leq M\left(t_{n+1}-s\right) .
$$

It follows from (2.1) that

$$
\begin{aligned}
& \left(x\left(h_{n}\right)-\lambda a\left(h_{n}\right)\right)^{2} \leq\left(\int_{-\infty}^{h_{n}} C\left(h_{n}, s\right) g(x(s)) d s\right)^{2} \\
& =\left(-\left.C\left(h_{n}, s\right) \int_{s}^{h_{n}} g(x(v)) d v d s\right|_{-\infty} ^{h_{n}}+\int_{-\infty}^{h_{n}} C_{s}\left(h_{n}, s\right) \int_{s}^{h_{n}} g(x(v)) d v d s\right)^{2} \\
& =\left(\int_{-\infty}^{h_{n}} C_{s}\left(h_{n}, s\right) \int_{s}^{h_{n}} g(x(v)) d v d s\right)^{2} \\
& \leq\left(\int_{-\infty}^{h_{n}}\left|C_{s}\left(h_{n}, s\right)\right| \int_{s}^{t_{n+1}}|g(x(v))| d v d s\right)^{2} \\
& \leq M^{2}\left(\int_{-\infty}^{h_{n}}\left|C_{s}\left(h_{n}, s\right)\right|\left(h_{n}+T-s\right) d s\right)^{2} .
\end{aligned}
$$

Since $\int_{-\infty}^{t}\left|C_{s}(t, s)\right| d s$ is T-periodic, we see from (2.15) that

$$
\sup _{0 \leq t \leq T} \int_{-\infty}^{t}\left|C_{s}(t, s)\right| d s \leq J_{0}
$$

for $\mathrm{J}_{0}>0$, and hence,

$$
\left(x\left(h_{n}\right)-\lambda a\left(h_{n}\right)\right)^{2} \leq M^{2}\left(J_{0}+J_{1}\right)^{2} .
$$

Noticing that $M$ is a function of $\mathrm{L}$, we find that

$$
\left|x\left(h_{n}\right)\right|<\|a\|+M\left(T_{0}+J_{1}\right)+1:=\gamma .
$$

This implies that $\|x\|<\gamma$ whenever $x$ is a T-periodic solution of (2.1) for $0 \leq \lambda \leq 1$, and the proof is complete.

We now define a mapping $\mathrm{F}$ on $\mathrm{P}_{\mathrm{T}}$ by

$$
\mathrm{F}(\phi)(\mathrm{t})=\mathrm{a}(\mathrm{t})-\int_{-\infty}^{\mathrm{t}} \mathrm{C}(\mathrm{t}, \mathrm{s}) \mathrm{g}(\phi(\mathrm{s})) \mathrm{ds} \text { for } \phi \in \mathrm{P}_{\mathrm{T}} \text {. }
$$


Theorem 2.3. If (2.3)-(2.5), (2.9)-(2,10) and (2.15) hold, then (2.1) has a T-periodic solution for $\lambda=1$.

Proof. It is clear that $\mathrm{F}(\phi) \in \mathrm{P}_{\mathrm{T}}$. We show that $\mathrm{F}$ is continuous on $\mathrm{P}_{\mathrm{T}}$ and is compact on each bounded subset of $\mathrm{P}_{\mathrm{T}}$. If $\tilde{\phi}, \phi \in \mathrm{P}_{\mathrm{T}}$, then

$$
\begin{aligned}
|F(\phi)(t)-F(\tilde{\phi})(t)| & =\left|\int_{-\infty}^{t} C(t, s) g(\phi(s)) d s-\int_{-\infty}^{t} C(t, s) g(\tilde{\phi}(s)) d s\right| \\
& =\left|\int_{-\infty}^{t} C_{s}(t, s)\left(\int_{s}^{t} g(\phi(v)) d v-\int_{s}^{t} g(\tilde{\phi}(v)) d v\right) d s\right| .
\end{aligned}
$$

Since $g$ is uniformly continuous on $\{x \in R:|x| \leq\|\tilde{\phi}\|+1\}$, for any $\varepsilon>0$,

there exists $0<\delta<1$ such that $\|\phi-\tilde{\phi}\|<\delta$ implies $|g(\phi(s))-g(\tilde{\phi}(s))|<\varepsilon$ for

all $s \in[0, T]$. It follows from $(2.18)$ that $\|\mathrm{F}(\phi)-\mathrm{F}(\tilde{\phi})\| \leq \mathrm{J}_{1} \varepsilon$. Thus, $\mathrm{F}$ is continuous on $\mathrm{P}_{\mathrm{T}}$.

We now show that $F$ is compact on each bounded subset of $\mathrm{P}_{\mathrm{T}}$. Let $\eta>0$ and define

$$
\Gamma=\left\{\mathrm{F}(\phi): \phi \in \mathrm{P}_{\mathrm{T}},\|\phi\| \leq \eta\right\} .
$$

Since

$$
\begin{aligned}
\frac{d}{d t} F(\phi)(t) & =a^{\prime}(t)-C(t, t) g(\phi(t))-\int_{-\infty}^{t} C_{t}(t, s) g(\phi(s)) d s \\
& =a^{\prime}(t)-C(t, t) g(\phi(t))-\int_{-\infty}^{t} D(t, s) g(\phi(s)) d s+k \int_{-\infty}^{t} C(t, s) g(\phi(s)) d s \\
& =a^{\prime}(t)-C(t, t) g(\phi(t))-\int_{-\infty}^{t} D(t, s) g(\phi(s)) d s+k \int_{-\infty}^{t} C_{s}(t, s) \int_{s}^{t} g(\phi(v)) d v d s
\end{aligned}
$$

we have

$$
\left|\frac{d}{d t} F(\phi)(t)\right| \leq\left\|a^{\prime}\right\|+g_{\eta} \sup _{0 \leq t \leq T}\left(|C(t, t)|+\int_{-\infty}^{t} D(t, s) d s+k \int_{-\infty}^{t}\left|C_{s}(t, s)\right|(t-s) d s\right)
$$

where $g_{\eta}=\{|g(x)|:|x| \leq \eta\}$, and thus, $\Gamma$ is equi-continuous. The uniform boundedness of $\Gamma$ follows from the inequality

$$
|\mathrm{F}(\phi)(\mathrm{t})| \leq\|\mathrm{a}\|+\int_{-\infty}^{\mathrm{t}}\left|\mathrm{C}_{s}(\mathrm{t}, \mathrm{s})\right| \int_{s}^{\mathrm{t}}|\mathrm{g}(\phi(v))| \mathrm{d} v \leq\|\mathrm{a}\|+\mathrm{J}_{1} \mathrm{~g}_{\eta}
$$

for all $\phi \in \Gamma$. So, by the Ascoli-Arzela theorem, $\Gamma$ lies in a compact subset of $\mathrm{P}_{\mathrm{T}}$. By combining Schaefer's theorem with Theorem 2.2, we see that $\mathrm{F}$ has a fixed point which is a T-periodic solution of (2.1) for $\lambda=1$. This completes the proof.

Corollary 2.1. Suppose that (2.3)-(2.5) hold. If there is an $\mathrm{L}>0$ and $\mu>0$ with

$$
x g(x) \geq 0 \text { for }|x| \geq L \text { and } C(t, t) \geq \mu
$$


then there is an $\mathrm{M}>0$ with

$$
\mathrm{V}^{\prime}(\mathrm{t}) \leq-|\mathrm{g}(\mathrm{x})|+\mathrm{M}
$$

whenever $\mathrm{x}$ is a T-periodic solution of (2.1). If, in addition, (2.15) is satisfied, then (2.1) has a $\mathrm{T}$-periodic solution for $\lambda=1$.

\section{Boundedness}

We turn now to

$$
x(t)=a(t)-\int_{0}^{t} C(t, s) g(x(s)) d s
$$

where $\mathrm{a}: \mathrm{R}^{+} \rightarrow \mathrm{R}, \mathrm{C}: \mathrm{R}^{+} \times \mathrm{R}^{+} \rightarrow \mathrm{R}, \mathrm{g}: \mathrm{R} \rightarrow \mathrm{R}$ are all continuous with $\mathrm{a}, \mathrm{a}^{\prime}$ bounded. The project here is to show that solutions of (3.1) are bounded. We define

$$
\mathrm{D}(\mathrm{t}, \mathrm{s}):=\mathrm{C}_{\mathrm{t}}(\mathrm{t}, \mathrm{s})+\mathrm{kC}(\mathrm{t}, \mathrm{s})
$$

for a constant $k>0$. Our main assumptions are that

$$
\mathrm{D}(\mathrm{t}, \mathrm{s}) \text { is convex for } \mathrm{t} \geq \mathrm{s} \geq 0
$$

and there exists $\mathrm{B}>0$ with

$$
C(t, t) \geq-B \text { and } \int_{0}^{t} D(t, s)(t-s) d s \leq B
$$

for all $t \geq 0$. We differentiate (3.1) and form

$$
x^{\prime}+k x=\left[a^{\prime}+k a-C(t, t) g(x)-\int_{0}^{t} D(t, s) g(x(s)) d s\right] .
$$

Now, we define the Liapunov functional

$$
V(t)=2 G(x(t))+\int_{0}^{t} D_{s}(t, s)\left(\int_{s}^{t} g(x(u)) d u\right)^{2} d s+D(t, 0)\left(\int_{0}^{t} g(x(u)) d u\right)^{2}
$$

for $x \in C\left(R^{+}, R\right)$, where $G(x)=\int_{0}^{x} g(s) d s$.

Theorem 3.1. Suppose that $\mathrm{D}(\mathrm{t}, \mathrm{s})$ is convex and $\mathrm{C}(\mathrm{t}, \mathrm{t}) \geq-\mathrm{B}$ for a constant $\mathrm{B}>0$. If $\mathrm{x}(\mathrm{t})$ is a solution of (3.1), then the derivative of $\mathrm{V}$ along that solution satisfies

$$
V^{\prime}(t) \leq 2 g(x)\left[a^{\prime}(t)+k a(t)\right]-2 g(x)[k x+C(t, t) g(x)] .
$$

If there is an $\mathrm{L}>0$ with

$$
x g(x) \geq 0 \text { for }|x| \geq L
$$


and if, in addition, there is $a \mu>0$ with

$$
g(x)[k x+C(t, t) g(x)] \geq \mu g^{2}(x)
$$

for $|x| \geq \mathrm{L}$, then there is an $\mathrm{M}>0$ with

$$
\mathrm{V}^{\prime}(\mathrm{t}) \leq-|\mathrm{g}(\mathrm{x})|+\mathrm{M}
$$

Proof. We first observe that if $x$ is a solution of (3.1), then $x$ is also a solution of (3.5). Now let $x$ be a solution (3.1) and $V(t)$ be defined in (3.6). We then find

$$
\begin{aligned}
V^{\prime}(t)= & 2 g(x) x^{\prime}(t)+\int_{0}^{t} D_{s t}(t, s)\left(\int_{s}^{t} g(x(u)) d u\right)^{2} d s \\
& +2 g(x(t)) \int_{0}^{t} D_{s}(t, s) \int_{s}^{t} g(x(u)) d u d s+D_{t}(t, 0)\left(\int_{0}^{t} g(x(u)) d u\right)^{2} \\
& +2 D(t, 0) g(x(t)) \int_{0}^{t} g(x(u)) d u .
\end{aligned}
$$

Integrate the third to last term by parts to obtain

$$
\begin{aligned}
& 2 g(x(t)) \int_{0}^{t} D_{s}(t, s) \int_{s}^{t} g(x(u)) d u d s \\
= & 2 g(x(t))\left[\left.D(t, s) \int_{s}^{t} g(x(u)) d u\right|_{s=0} ^{s=t}+\int_{0}^{t} D(t, s) g(x(s)) d s\right] \\
= & 2 g(x(t))\left[-D(t, 0) \int_{0}^{t} g(x(s)) d s+\int_{0}^{t} D(t, s) g(x(s)) d s\right] .
\end{aligned}
$$

Cancel terms, use the sign conditions, and use (3.5) in the process to unite the Liapunov functional and the equation to obtain

$$
\begin{aligned}
V^{\prime}(t) \leq & 2 g(x)\left[-k x+\left(a^{\prime}+k a\right)-C(t, t) g(x)-\int_{0}^{t} D(t, s) g(x(s)) d s\right] \\
& +2 g(x) \int_{0}^{t} D(t, s) g(x(s)) d s \\
= & 2 g(x)\left[a^{\prime}(t)+k a(t)\right]-2 g(x)[k x+C(t, t) g(x)]
\end{aligned}
$$

verifying (3.7).

Now we assume that (3.8) and (3.9) hold. We may choose $N>1$ so large that $\mu(N-1)>B$, where $B$ and $\mu$ are defined in (3.4) and (3.9), respectively. If $|x| \geq L$, then $x g(x) \geq 0$, and by (3.9), 
we obtain for $|x(t)| \geq L$ that

$$
\begin{aligned}
V^{\prime}(t) \leq & 2|g(x)|\left[\left|a^{\prime}\right|+k|a|\right]-2 g(x)[k x+C(t, t) g(x)] \\
= & 2|g(x)|\left[\left|a^{\prime}\right|+k|a|\right]-2 k \frac{1}{N} x g(x) \\
& -2\left(1-\frac{1}{N}\right) g(x)[k x+C(t, t) g(x)]-2 \frac{1}{N} C(t, t) g^{2}(x) \\
\leq & 2|g(x)|\left[\left|a^{\prime}\right|+k|a|\right]-2 k \frac{1}{N} x g(x) \\
& -2\left(1-\frac{1}{N}\right) \mu g^{2}(x)+2 \frac{1}{N} B g^{2}(x) \\
\leq & -2|g(x)|\left[\frac{1}{N} k|x|-\left(\left|a^{\prime}(t)\right|+k|a(t)|\right)\right] .
\end{aligned}
$$

We may assume that

$$
L \geq N\left[\sup _{t \geq 0}\left(\left|a^{\prime}(t)\right|+k|a(t)|\right)+1\right] / k .
$$

Thus, if $|x(t)| \geq L$, then $V^{\prime}(t) \leq-|g(x(t))|$. Since $-C(t, t) \leq B$, it is clear that $V^{\prime}(t) \leq M$ for $0 \leq|x(t)| \leq L$, where the constant $M>0$ is a function of $L$, and hence,

$$
V^{\prime}(t) \leq-|g(x(t))|+M
$$

for all $t \geq 0$. This completes the proof.

Relations related to (3.9) and (3.10) are found in [4].

To establish the boundedness of solutions, we assume that there is a $B_{1}>0$ with

$$
|C(t, 0)| t \leq B_{1} \text { and } \int_{0}^{t}\left|C_{s}(t, s)\right|(t-s+1) d s \leq B_{1}
$$

for $t \geq 0$. We also observe that

$$
\begin{aligned}
\int_{0}^{t} D_{s}(t, s)(t-s)^{2} d s & =\left.D(t, s)(t-s)^{2}\right|_{0} ^{t}+2 \int_{0}^{t} D(t, s)(t-s) d s \\
& =-D(t, 0) t^{2}+2 \int_{0}^{t} D(t, s)(t-s) d s
\end{aligned}
$$

By (3.4), we now have

$$
\int_{0}^{t} D_{s}(t, s)(t-s)^{2} d s+D(t, 0) t^{2}=2 \int_{0}^{t} D(t, s)(t-s) d s \leq 2 B
$$

for all $t \geq 0$. 
Theorem 3.2. If (3.3)-(3.4), (3.8)-(3.9), and (3.12) hold, then any solution of (3.1) is bounded.

Proof. Let $\mathrm{x}$ be a solution of (3.1) and $\mathrm{V}(\mathrm{t})$ be defined in (3.6). Then $\mathrm{V}(\mathrm{t})$ is bounded below and satisfies (3.10). We now show that $\mathrm{V}(\mathrm{t})$ is bounded above. If $\mathrm{V}(\mathrm{t})$ is unbounded, then there exists a sequence $\left\{t_{n}\right\} \uparrow \infty$ with $V\left(t_{n}\right) \rightarrow \infty$ as $n \rightarrow \infty$ and

$$
V\left(t_{n}\right) \geq V(s) \text { for } 0 \leq s \leq t_{n}
$$

It then follows from (3.10) that

$$
0 \leq \mathrm{V}\left(\mathrm{t}_{\mathrm{n}}\right)-\mathrm{V}(\mathrm{s}) \leq-\int_{\mathrm{s}}^{\mathrm{t}_{\mathrm{n}}}|\mathrm{g}(\mathrm{x}(\mathrm{u}))| \mathrm{du}+\mathrm{M}\left(\mathrm{t}_{\mathrm{n}}-\mathrm{s}\right) .
$$

This implies that

$$
\int_{s}^{t_{n}}|g(x(u))| d u \leq M\left(t_{n}-s\right) .
$$

Applying (3.14) to $V\left(t_{n}\right)$ and taking into account (3.13), we find that

$$
\begin{aligned}
V\left(t_{n}\right) & \leq 2 G\left(x\left(t_{n}\right)\right)+M^{2}\left[\int_{0}^{t_{n}} D_{s}\left(t_{n}, s\right)\left(t_{n}-s\right)^{2} d s+D\left(t_{n}, 0\right) t^{2}\right] \\
& \leq 2 G\left(x\left(t_{n}\right)\right)+2 B M^{2} .
\end{aligned}
$$

We now use (3.1), (3.12), and (3.14) to obtain

$$
\begin{aligned}
\left(x\left(t_{n}\right)-a\left(t_{n}\right)\right)^{2} & =\left(\int_{0}^{t_{n}} C\left(t_{n}, s\right) g(x(s)) d s\right)^{2} \\
& =\left(-\left.C\left(t_{n}, s\right) \int_{s}^{t_{n}} g(x(u)) d u\right|_{s=0} ^{s=t_{n}}+\int_{0}^{t_{n}} C_{s}\left(t_{n}, s\right) \int_{s}^{t_{n}} g(x(u)) d u d s\right)^{2} \\
& =\left(C\left(t_{n}, 0\right) \int_{0}^{t_{n}} g(x(s)) d s+\int_{0}^{t_{n}} C_{s}\left(t_{n}, s\right) \int_{s}^{t_{n}} g(x(u)) d u d s\right)^{2} \\
& \leq\left(\left|C\left(t_{n}, 0\right)\right| M t_{n}+M \int_{0}^{t_{n}}\left|C_{s}\left(t_{n}, s\right)\right|\left(t_{n}-s\right) d s\right)^{2} \leq M^{2}\left(2 B_{1}\right)^{2} .
\end{aligned}
$$

This implies that

$$
\left|x\left(t_{n}\right)\right| \leq \sup _{s \geq 0}|a(s)|+2 B_{1} M:=B_{2}
$$

and that $\left|G\left(x\left(t_{n}\right)\right)\right| \leq B_{3}$ for a $B_{3}>0$. We now find that

$$
\mathrm{V}\left(\mathrm{t}_{\mathrm{n}}\right) \leq 2 \mathrm{G}\left(\mathrm{x}\left(\mathrm{t}_{\mathrm{n}}\right)\right)+2 \mathrm{BM}^{2} \leq 2 \mathrm{~B}_{3}+2 \mathrm{BM}^{2}:=\mathrm{B}_{4},
$$


a contradiction. Thus, $\mathrm{V}(\mathrm{t})$ is bounded. In fact, we have

$$
2 \mathrm{G}(x(\mathrm{t})) \leq \mathrm{V}(\mathrm{t}) \leq 2 \mathrm{G}(\mathrm{x}(0))+\mathrm{B}_{4}
$$

and hence

$$
|\mathrm{V}(\mathrm{t})| \leq \mathrm{K} \text { for all } \mathrm{t} \geq 0
$$

where $K:=2|\eta|+2|G(x(0))|+B_{4}$ where $\eta=\inf \{G(u): u \in R\}$. We also observe that $|C(t, 0)| \leq B_{5}$ for a $B_{5}>0$ whenever (3.12) holds.

We now integrate (3.10) from $s$ to $t$ and use (3.18) to obtain

$$
\int_{s}^{t}|g(x(u))| d u \leq V(s)-V(t)+M(t-s) \leq 2 K+M(t-s)
$$

Applying (3.19) to (3.1) we find

$$
\begin{aligned}
|x(t)| & \leq|a(t)|+\left|\int_{0}^{t} C(t, s) g(x(s)) d s\right| \\
& \leq|a(t)|+\left|C(t, 0) \int_{0}^{t} g(x(s)) d s+\int_{0}^{t} C_{s}(t, s) \int_{s}^{t} g(x(u)) d u d s\right| \\
& \leq|a(t)|+|C(t, 0)|(M t+2 K)+\int_{0}^{t}\left|C_{s}(t, s)\right|[M(t-s)+2 K] d s \\
& \leq \sup _{s \geq 0}|a(s)|+B_{1} M+2 K B_{5}+B_{1}(M+2 K) .
\end{aligned}
$$

This implies that $x$ is bounded. The proof is complete.

Corollary 3.1. Suppose that (3.3)-(3.4) hold. If there is an $\mathrm{L}>0$ and $\mu>0$ with

$$
x g(x) \geq 0 \text { for }|x| \geq L \text { and } C(t, t) \geq \mu
$$

then there is an $\mathrm{M}>0$ with

$$
\mathrm{V}^{\prime}(\mathrm{t}) \leq-|g(x)|+M
$$

whenever $\mathrm{x}$ is a solution of (3.1). If, in addition, (3.12) holds, then $\mathrm{V}(\mathrm{t})$ satisfies (3.17) and any solution of (3.1) is bounded.

Remark 3.1. Inequalities related to (3.17) and (3.21) are of fundamental importance in the study of boundedness and periodic solutions in differential equations by Liapunov's direct method (see Burton [3] and Yoshizawa [18]). Not only are these practical inequalities with many applications, but such combined relations are directly linked to the right-hand side of the equations, and hence, 
much of the qualitative properties of solutions can be derived by taking full advantage of the Liapunov functions.

The following example shows that if $C(t, s)$ is not convex while $D(t, s)$ is, then the combined equation (1.7) is the right form to apply Liapunov functionals.

Example 3.1. We consider the equation

$$
x(t)=a(t)-\int_{0}^{t} C(t, s) g(x(s)) d s
$$

where $a: R^{+} \rightarrow R$ and $g: R \rightarrow R$ are continuous with $a, a^{\prime}$ bounded, and

$$
C(t, s)=C(t-s)=-e^{-(t-s+3)^{2}} \text { for } t \geq s \geq 0 .
$$

It is clear that $C(t, s)$ is not convex (even not positive). If we choose $k=4$, then

$$
\mathrm{D}(\mathrm{t}, \mathrm{s})=\mathrm{C}_{\mathrm{t}}(\mathrm{t}, \mathrm{s})+\mathrm{kC}(\mathrm{t}, \mathrm{s})=2(\mathrm{t}-\mathrm{s}+1) \mathrm{e}^{-(\mathrm{t}-\mathrm{s}+3)^{2}} .
$$

A straightforward calculation shows that $\mathrm{D}(\mathrm{t}, \mathrm{s})$ is convex and (3.4) holds. We also see that $\mathrm{C}(\mathrm{t}, \mathrm{s})$ satisfies (3.12). Thus, if there exist constants $L>0$ and $\mu>0$ with $x g(x) \geq 0$ for $|x| \geq L$ and

$$
g(x)[k x+C(t, t) g(x)]=g(x)\left[4 x-e^{-9} g(x)\right] \geq \mu g^{2}(x)
$$

for $|x| \geq \mathrm{L}$, then any solution of (3.22) is bounded by Theorem 3.2.

\section{A Truncated Equation and Unification}

We consider the finite delay equation

$$
x(t)=a(t)-\int_{t-h}^{t} C(t, s) g(x(s)) d s
$$

in which $h>0$ is a constant, $a: R^{+} \rightarrow R, C: R^{+} \times[-h, \infty) \rightarrow R, g: R \rightarrow R$ are all continuous with $a, a^{\prime}$ bounded. We write

$$
\mathrm{D}(\mathrm{t}, \mathrm{s}):=\mathrm{C}_{\mathrm{t}}(\mathrm{t}, \mathrm{s})+\mathrm{kC}(\mathrm{t}, \mathrm{s})
$$

for a positive constant $k$ and assume that $D(t, s)$ is convex:

$$
D(t, s) \geq 0, D_{s}(t, s) \geq 0, D_{s t}(t, s) \leq 0, D_{t}(t, s) \leq 0
$$

for $t \geq s \geq-h$ and that

$$
C(t, t-h)=0, \quad C_{t}(t, t-h)=0, \quad C(t, t) \geq-B
$$


for all $t \geq 0$ and a constant $B>0$, where $C_{t}(t, t-h)$ is the partial derivative of $C(t, s)$ with respect the first variable for $\mathrm{s}=\mathrm{t}-\mathrm{h}$.

Before we get too far into the work, it is interesting to point out classical forms for C. Let

$$
C(t, s)=C(t-s)=(-1)^{n}(t-s-h)^{n}, n>2 .
$$

Not only does it satisfy (4.4), but it is a convex kernel for $0 \leq \mathrm{s} \leq \mathrm{t} \leq \mathrm{h}$. Moreover, if we let $C(t)=0$ for $t>h$ then that kernel will satisfy our work in both Sections 2 and 3. In Section 3 something very interesting happens. In the linear case we have

$$
x(t)=a(t)-\int_{0}^{t} C(t-s) x(s) d s
$$

an equation about which there is a very straightforward theory. However, for $t \geq h$ it becomes

$$
x(t)=a(t)-\int_{t-h}^{t} C(t-s) x(s) d s
$$

and that belongs to a class of far more complex structure.

We differentiate (4.1) and take into account (4.4) to form

$$
x^{\prime}+k x=\left[a^{\prime}+k a-C(t, t) g(x)-\int_{t-h}^{t} D(t, s) g(x(s)) d s\right] .
$$

Now, we define the Liapunov functional

$$
V(t)=2 G(x(t))+\int_{t-h}^{t} D_{s}(t, s)\left(\int_{s}^{t} g(x(u)) d u\right)^{2} d s
$$

for $x \in C([-h, \infty), R)$, where $G(x)=\int_{0}^{x} g(s) d s$.

Theorem 4.1. Suppose that (4.3) and (4.4) hold. If $x(\mathrm{t})$ is a solution of (4.1), then the derivative of $\mathrm{V}$ along that solution satisfies

$$
V^{\prime}(t) \leq 2 g(x)\left[a^{\prime}(t)+k a(t)\right]-2 g(x)[k x+C(t, t) g(x)] .
$$

If there is an $\mathrm{L}>0$ with

$$
x g(x) \geq 0 \text { for }|x| \geq L
$$

and if, in addition, there is $a \mu>0$ with

$$
g(x)[k x+C(t, t) g(x)] \geq \mu g^{2}(x)
$$

for $|x| \geq \mathrm{L}$, then there is an $\mathrm{M}>0$ with

$$
\mathrm{V}^{\prime}(\mathrm{t}) \leq-|\mathrm{g}(\mathrm{x})|+M
$$


for all $\mathrm{t} \geq 0$.

Proof. We first observe that if $x$ is a solution of (4.1), then $x$ is also a solution of (4.5). Now let $x$ be a solution (4.1) and $\mathrm{V}(\mathrm{t})$ be defined in (4.6). We then find that

$$
\begin{aligned}
V^{\prime}(t)= & 2 g(x) x^{\prime}(t)+\int_{t-h}^{t} D_{s t}(t, s)\left(\int_{s}^{t} g(x(u)) d u\right)^{2} d s \\
& -D_{s}(t, t-h)\left(\int_{t-h}^{t} g(x(u)) d u\right)^{2}+2 g(x(t)) \int_{t-h}^{t} D_{s}(t, s) \int_{s}^{t} g(x(u)) d u d s .
\end{aligned}
$$

Integration of the last term by parts and use of (4.4) yield

$$
\begin{aligned}
& 2 g(x(t)) \int_{t-h}^{t} D_{s}(t, s) \int_{s}^{t} g(x(u)) d u d s \\
= & 2 g(x(t))\left[\left.D(t, s) \int_{s}^{t} g(x(u)) d u\right|_{s=t-h} ^{s=t}+\int_{t-h}^{t} D(t, s) g(x(s)) d s\right] \\
= & 2 g(x(t)) \int_{t-h}^{t} D(t, s) g(x(s)) d s .
\end{aligned}
$$

Since $D_{s t}(t, s) \leq 0$ and $D_{s}(t, t-h) \geq 0$, the middle two terms of $V^{\prime}$ are not positive, and if we use (4.5) and (4.11), we obtain

$$
\begin{aligned}
V^{\prime}(t) \leq & 2 g(x)\left[-k x+\left(a^{\prime}+k a\right)-C(t, t) g(x)-\int_{t-h}^{t} D(t, s) g(x(s)) d s\right] \\
& +2 g(x) \int_{t-h}^{t} D(t, s) g(x(s)) d s \\
= & 2 g(x)\left[a^{\prime}(t)+k a(t)\right]-2 g(x)[k x+C(t, t) g(x)]
\end{aligned}
$$

verifying (4.7).

Now we assume that (4.8) and (4.9) hold. We may choose $N>1$ so large that $\mu(N-1)>-B$, where B and $\mu$ are defined in (4.4) and (4.9), respectively. If $|x| \geq L$, then $x g(x) \geq 0$, and by (4.9), 
we obtain for $|x(t)| \geq L$ that

$$
\begin{aligned}
V^{\prime}(t) \leq & 2|g(x)|\left[\left|a^{\prime}\right|+k|a|\right]-2 g(x)[k x+C(t, t) g(x)] \\
= & 2|g(x)|\left[\left|a^{\prime}\right|+k|a|\right]-2 k \frac{1}{N} x g(x) \\
& -2\left(1-\frac{1}{N}\right) g(x)[k x+C(t, t) g(x)]-2 \frac{1}{N} C(t, t) g^{2}(x) \\
\leq & 2|g(x)|\left[\left|a^{\prime}\right|+k|a|\right]-2 k \frac{1}{N} x g(x) \\
& -2\left(1-\frac{1}{N}\right) \mu g^{2}(x)+2 \frac{1}{N} B g^{2}(x) \\
\leq & -2|g(x)|\left[\frac{1}{N} k|x|-\left(\left|a^{\prime}(t)\right|+k|a(t)|\right)\right] .
\end{aligned}
$$

We may assume that

$$
L \geq N\left[\sup _{t \geq 0}\left(\left|a^{\prime}(t)\right|+k|a(t)|\right)+1\right] / k .
$$

Thus, if $|x(t)| \geq L$, then $V^{\prime}(t) \leq-|g(x(t))|$. Since $-C(t, t) \leq B$, it is clear that $V^{\prime}(t) \leq M$ for $0 \leq|x(t)| \leq L$, where the constant $M>0$ is a function of $L$, and hence,

$$
V^{\prime}(t) \leq-|g(x(t))|+M
$$

for all $t \geq 0$. This completes the proof.

To establish boundedness of solutions, we assume that there is a $B_{1}>0$ with

$$
\mathrm{D}(\mathrm{t}, \mathrm{t}) \leq \mathrm{B}_{1} \text { and } \int_{\mathrm{t}-\mathrm{h}}^{\mathrm{t}}\left|\mathrm{C}_{\mathrm{s}}(\mathrm{t}, \mathrm{s})\right| \mathrm{d} s \leq \mathrm{B}_{1}
$$

for $t \geq 0$. We then see that

$$
\int_{t-h}^{t} D_{s}(t, s) d s=D(t, t) \leq B_{1} \text { and }|C(t, t)| \leq \int_{t-h}^{t}\left|C_{s}(t, s)\right| d s \leq B_{1} .
$$

Theorem 4.2. If (4.3)-(4.4), (4.8)-(4.9), and (4.12) hold, then any solution of (4.1) is bounded.

Proof. Let $x$ be a solution of (4.1) and $\mathrm{V}(\mathrm{t})$ be defined in (4.6). Then $\mathrm{V}(\mathrm{t})$ is bounded below and satisfies (4.10). We now show that $\mathrm{V}(\mathrm{t})$ is bounded above. If $\mathrm{V}(\mathrm{t})$ is unbounded, then there exists a sequence $\left\{t_{n}\right\} \uparrow \infty$ with $V\left(t_{n}\right) \rightarrow \infty$ as $n \rightarrow \infty$ and

$$
V\left(t_{n}\right) \geq V(s) \text { for } 0 \leq s \leq t_{n}
$$


It then follows from (4.10) that

$$
0 \leq V\left(t_{n}\right)-V(s) \leq-\int_{s}^{t_{n}}|g(x(u))| d u+M\left(t_{n}-s\right) .
$$

This implies that

$$
\int_{s}^{t_{n}}|g(x(u))| d u \leq M\left(t_{n}-s\right)
$$

and, in particular, that

$$
\int_{s}^{t_{n}}|g(x(u))| d u \leq M\left(t_{n}-s\right) \leq h M
$$

for all $t_{n}-h \leq s \leq t_{n}$. Applying (4.14) to (4.1), We see that

$$
\begin{aligned}
\left(x\left(t_{n}\right)-a\left(t_{n}\right)\right)^{2} & =\left(\int_{t_{n}-h}^{t_{n}} C\left(t_{n}, s\right) g(x(s)) d s\right)^{2} \\
& =\left(-\left.C\left(t_{n}, s\right) \int_{s}^{t_{n}} g(x(s)) d s\right|_{s=t_{n}-h} ^{s=t_{n}}+\int_{t_{n}-h}^{t_{n}} C_{s}\left(t_{n}, s\right) \int_{s}^{t_{n}} g(x(u)) d u d s\right)^{2} \\
& =\left(\int_{t_{n}-h}^{t_{n}} C_{s}\left(t_{n}, s\right) \int_{s}^{t_{n}} g(x(u)) d u d s\right)^{2} \\
& \leq\left(h M \int_{t_{n}-h}^{t_{n}}\left|C_{s}\left(t_{n}, s\right)\right| d s\right)^{2} \leq h^{2} B_{1}^{2} M^{2} .
\end{aligned}
$$

This implies that

$$
\left|x\left(t_{n}\right)\right| \leq \sup _{s \geq 0}|a(s)|+h B_{1} M:=B_{2}
$$

and that $\left|G\left(x\left(t_{n}\right)\right)\right| \leq B_{3}$ for a $B_{3}>0$. We now arrive at

$$
\begin{aligned}
V\left(t_{n}\right) & =2 G\left(x\left(t_{n}\right)\right)+\int_{t_{n}-h}^{t_{n}} D_{s}\left(t_{n}, s\right)\left(\int_{s}^{t_{n}} g(x(u)) d u\right)^{2} d s \\
& \leq 2 G\left(x\left(t_{n}\right)\right)+h^{2} M^{2} \int_{t_{n}-h}^{t_{n}} D_{s}\left(t_{n}, s\right) d s \\
& \leq 2 B_{3}+B_{1} h^{2} M^{2}:=B_{4},
\end{aligned}
$$

a contradiction. Thus, $\mathrm{V}(\mathrm{t})$ is bounded. In fact, we have

$$
2 \mathrm{G}(x(\mathrm{t})) \leq \mathrm{V}(\mathrm{t}) \leq \max \left\{\mathrm{V}(0), \mathrm{B}_{4}\right\}
$$

and hence

$$
|V(t)| \leq K \text { for all } t \geq 0
$$


where $\mathrm{K}:=2|\eta|+2|\mathrm{G}(x(0))|+\mathrm{B}_{4}$ with $\eta=\inf \{\mathrm{G}(\mathrm{u}): \mathrm{u} \in \mathrm{R}\}$.

We now integrate (4.10) from $s$ to $t$ and use (4.17) to obtain

$$
\int_{s}^{t}|g(x(u))| d u \leq V(s)-V(t)+M(t-s) \leq 2 K+M(t-s)
$$

and hence

$$
\int_{s}^{t}|g(x(u))| d u \leq 2 K+h M \text { for } t_{n}-h \leq s \leq t_{n} .
$$

Applying (4.18) to (4.1) we find that

$$
\begin{aligned}
|x(t)| & \leq|a(t)|+\left|\int_{t-h}^{t} C(t, s) g(x(s)) d s\right| \\
& \leq|a(t)|+\left|C(t, t-h) \int_{t-h}^{t} g(x(s)) d s+\int_{t-h}^{t} C_{s}(t, s) \int_{s}^{t} g(x(u)) d u d s\right| \\
& \leq|a(t)|+\int_{t-h}^{t}\left|C_{s}(t, s)\right|[2 K+h M] d s \\
& \leq \sup _{s \geq 0}|a(s)|+B_{1}(2 K+h M) .
\end{aligned}
$$

This implies that $x$ is bounded. The proof is complete.

We now consider the existence of periodic solutions of (4.1). We assume that $a: R \rightarrow R, C$ : $R \times R \rightarrow R$, and $g: R \rightarrow R$ are continuous and that there is a $T>0$ with

$$
a(t+T)=a(t), C(t+T, s+T)=C(t, s)
$$

for all $t \geq s$. If (4.20) holds, then $C(t, t)$ and $\int_{t-h}^{t}\left|C_{s}(t, s)\right| d s$ are $T$-periodic, and so there are $B$ and $B_{1}$ with

$$
C(t, t) \geq-B, \quad \int_{t-h}^{t}\left|C_{s}(t, s)\right| d s \leq B_{1}
$$

then part of (4.4) and (4.12) are satisfied. We define a companion of (4.1) by

$$
x(t)=\lambda\left[a(t)-\int_{t-h}^{t} C(t, s) g(x(s)) d s\right], 0 \leq \lambda \leq 1
$$

for $t \in R$ and form a differential equation

$$
x^{\prime}+k x=\lambda\left[a^{\prime}+k a-C(t, t) g(x)-\int_{t-h}^{t} D(t, s) g(x(s)) d s\right] .
$$


To obtain an a priori bound for all T-periodic solutions of (4.21), we define

$$
V_{1}(t)=2 G(x(t))+\lambda \int_{t-h}^{t} D_{s}(t, s)\left(\int_{s}^{t} g(x(u)) d u\right)^{2} d s
$$

for $\mathrm{t} \in \mathrm{R}$ and $\mathrm{x} \in\left(\mathrm{P}_{\mathrm{T}},\|\cdot\|\right)$.

Theorem 4.3. If (4.3)-(4.4), (4.8)-(4.9), and (4.20) hold for $\mathrm{t} \geq \mathrm{s}$, then (4.1) has a T-periodic solution.

Proof. Let $\mathrm{x}$ be a T-periodic solution of (4.21) and $\mathrm{V}_{\mathbf{1}}(\mathrm{t})$ be defined in (4.23). Then we have

$$
V_{1}^{\prime}(t) \leq-|g(x)|+M
$$

for $t \geq 0$ and for an $M>0$ independent of $x$ and $\lambda$. Since $V_{1}(t)$ is T-periodic, $V_{1}(t)$ has a global maximum at $\mathrm{q} \in[0, \mathrm{~T}]$, and hence, at $\mathrm{t}_{\mathrm{n}}=\mathrm{q}+\mathrm{nT}$. We then have

$$
0 \leq V_{1}\left(t_{n}\right)-V_{1}(s) \leq-\int_{s}^{t_{n}}|g(x(u))| d u+M\left(t_{n}-s\right)
$$

for all $s \leq t_{n}$. An argument similar to that of (4.13)-(4.16) shows that $V_{1}\left(t_{n}\right) \leq B_{4}$ with $B_{4}$ defined just after (4.16). Observing that

$$
V_{1}(0) \leq V_{1}\left(t_{n}\right) \leq B_{4},
$$

we see that $\left|V_{1}(t)\right| \leq K$ with $K=2|\eta|+B_{4}$, where $\eta=\inf \{G(u): u \in R\}$. We then follow the argument in (4.19) to arrive at

$$
\left.|x(t)|<\sup _{s \geq 0}|a(s)|+B_{1}(2 K+h M)\right)+1:=B^{*}
$$

for all $t \in R$. This implies that $\|x\|<B^{*}$ whenever $x$ is a T-periodic solution of (4.21) for $0 \leq \lambda \leq 1$.

Define a mapping $\mathrm{F}$ on $\mathrm{P}_{\mathrm{T}}$ by

$$
F(\phi)(t)=a(t)-\int_{t-h}^{t} C(t, s) g(\phi(s)) d s
$$

for each $\phi \in \mathrm{P}_{\mathrm{T}}$. It is clear that $\mathrm{F}(\phi) \in \mathrm{P}_{\mathrm{T}}$. We will show that $\mathrm{F}$ is continuous on $\mathrm{P}_{\mathrm{T}}$ and is compact on each bounded subset of $\mathrm{P}_{\mathrm{T}}$. If $\tilde{\phi}, \phi \in \mathrm{P}_{\mathrm{T}}$, then

$$
\begin{aligned}
|F(\phi)(t)-F(\tilde{\phi})(t)| & =\left|\int_{t-h}^{t} C(t, s) g(\phi(s)) d s-\int_{t-h}^{t} C(t, s) g(\tilde{\phi}(s)) d s\right| \\
& =\left|\int_{t-h}^{t} C_{s}(t, s)\left(\int_{s}^{t} g(\phi(v)) d v-\int_{s}^{t} g(\tilde{\phi}(v)) d v\right) d s\right| .
\end{aligned}
$$


Since $g$ is uniformly continuous on $\{x \in R:|x| \leq\|\tilde{\phi}\|+1\}$, then for any $\varepsilon>0$, there exists $0<\delta<1$ such that $\|\phi-\tilde{\phi}\|<\delta$ implies $|g(\phi(s))-g(\tilde{\phi}(s))|<\varepsilon$ for all $s \in[0, T]$. It follows from (4.27) that $\|\mathrm{F}(\phi)-\mathrm{F}(\tilde{\phi})\| \leq h B_{1} \varepsilon$. Thus, $\mathrm{F}$ is continuous on $\mathrm{P}_{\mathrm{T}}$.

We now show that $F$ is compact on each bounded subset of $P_{T}$. Let $\eta>0$ and define

$$
\Gamma=\left\{\mathrm{F}(\phi): \phi \in \mathrm{P}_{\mathrm{T}},\|\phi\| \leq \eta\right\} .
$$

Observe that

$$
\begin{aligned}
\frac{d}{d t} F(\phi)(t) & =a^{\prime}(t)-C(t, t) g(\phi(t))-\int_{t-h}^{t} C_{t}(t, s) g(\phi(s)) d s \\
& =a^{\prime}(t)-C(t, t) g(\phi(t))-\int_{t-h}^{t} D(t, s) g(\phi(s)) d s+k \int_{t-h}^{t} C(t, s) g(\phi(s)) d s \\
& =a^{\prime}(t)-C(t, t) g(\phi(t))-\int_{t-h}^{t} D(t, s) g(\phi(s)) d s+k \int_{t-h}^{t} C_{s}(t, s) \int_{s}^{t} g(\phi(v)) d v d s
\end{aligned}
$$

and that

$$
\begin{aligned}
\left|\frac{d}{d t} F(\phi)(t)\right| & \leq\left\|a^{\prime}\right\|+g^{*} \sup _{0 \leq t \leq T}\left[|C(t, t)|+\int_{t-h}^{t} D(t, s) d s+k \int_{t-h}^{t}\left|C_{s}(t, s)\right|(t-s) d s\right] \\
& \leq\left\|a^{\prime}\right\|+g^{*}\left[\sup _{0 \leq t \leq T}|C(t, t)|+h B_{1}+h k B_{1}\right]
\end{aligned}
$$

where $\mathrm{g}^{*}=\sup \{|\mathrm{g}(\mathfrak{u})|:|\mathfrak{u}| \leq \eta\}$; thus, $\Gamma$ is equi-continuous. The uniform boundedness of $\Gamma$ follows from the inequality

$$
|F(\phi)(t)| \leq\|a\|+\int_{t-h}^{t}\left|C_{s}(t, s)\right| \int_{s}^{t}|g(\phi(v))| d v \leq\|a\|+h B_{1} g^{*}
$$

for all $\phi \in \Gamma$. So, by the Ascoli-Arzela theorem, $\Gamma$ lies in a compact subset of $\mathrm{P}_{\mathrm{T}}$. By Schaefer's theorem, we see $\mathrm{F}$ has a fixed point which is a T-periodic solution of (4.1). The proof is complete.

We now give two examples which show a connection between this section and Sections 2 and 3.

Example 1. Consider the scalar equation

$$
x(t)=a(t)-\int_{-\infty}^{t} C(t-s) g(x(s)) d s
$$

where

$$
\begin{aligned}
\mathrm{C}(\mathrm{t}) & =(-1)^{\mathrm{n}}(\mathrm{t}-\mathrm{h})^{\mathrm{n}}, 0 \leq \mathrm{t} \leq \mathrm{h}, \mathrm{n}=3,4, . . \\
& =0, \mathrm{t} \geq \mathrm{h}
\end{aligned}
$$


for some $h>0$. It is readily verified that $C^{\prime \prime}$ is continuous for $0 \leq t<\infty$ and that $C(t-s)$ is convex. Moreover, using two changes of variable we find that

$$
\begin{aligned}
x(t) & =a(t)-\int_{0}^{\infty} C(u) g(x(t-u)) d u \\
& =a(t)-\int_{0}^{h} C(u) g(x(t-u)) d u \\
& =a(t)-\int_{t-h}^{t} C(t-s) g(x(s)) d s
\end{aligned}
$$

and $C(h)=C^{\prime}(h)=C^{\prime \prime}(h)=0$. All of the work in Sections 2 and 4 hold for this equation.

Example 2. Consider

$$
x(t)=a(t)-\int_{0}^{t} C(t-s) g(x(s)) d s
$$

with solution $\phi$ on $[0, h]$ where $C$ satisfies (4.30). Then for $t \geq h$ we have

$$
x(t)=a(t)-\int_{t-h}^{t} C(t-s) g(x(s)) d s, t \geq h,
$$

with initial function $\phi$ on $[0, h]$.

Theorem 4.4 Let $\frac{\mathrm{d} g(x)}{\mathrm{d} x}$ be continuous, let $\mathrm{x}(\mathrm{t})$ be the unique solution of (4.32), and let $\mathrm{y}(\mathrm{t})$ be any continuous solution of (4.33). Suppose that there is an $\mathrm{L}>0$ with $\frac{\mathrm{d} g(\mathrm{x})}{\mathrm{dx}} \geq \mathrm{L}$. Then $z(\mathrm{t}):=\mathrm{x}(\mathrm{t})-\mathrm{y}(\mathrm{t}) \in \mathrm{L}^{2}[\mathrm{~h}, \infty)$. If, in addition, there is an $\mathrm{M}>0$ with $\frac{\mathrm{dg}(\mathrm{x})}{\mathrm{d} x} \leq \mathrm{M}$, then $z(\mathrm{t}) \rightarrow 0$ as $\mathrm{t} \rightarrow \infty$.

Proof. We have for $\mathrm{t} \geq \mathrm{h}$ that

$$
\begin{aligned}
z(t) & =-\int_{t-h}^{t} C(t-s)[g(x(s)-g(y(s))] d s \\
& =-\int_{t-h}^{t} C(t-s) \frac{d g(\xi(s))}{d x} z(s) d s
\end{aligned}
$$

where $\xi(s)$ is between $x(s)$ and $y(s)$. Define a Liapunov functional by

$$
V(t)=\int_{t-h}^{t} C_{s}(t-s)\left(\int_{s}^{t}[g(x(u))-g(y(u))] d u\right)^{2} d s
$$

with derivative satisfying

$$
V^{\prime}(t) \leq-2[g(x(t))-g(y(t))][x(t)-y(t)]=-2 \frac{d g(\xi(t))}{d x} z^{2}(t) \leq-2 L z^{2}(t) .
$$


This yields the first conclusion. With the last assumption, note that

$$
\begin{aligned}
|z(t)| & \leq M \int_{t-h}^{t}|C(t-s)||z(s)| d s \\
& \leq M \sqrt{\int_{t-h}^{t} C^{2}(t-s) d s \int_{t-h}^{t} z^{2}(s) d s} \\
& \leq M \sqrt{h^{2 n+1} \int_{t-h}^{t} z^{2}(s) d s}
\end{aligned}
$$

and

$$
\int_{t-h}^{t} z^{2}(s) d s \rightarrow 0 \text { as } t \rightarrow \infty .
$$

Under the conditions here, with $C$ defined by (4.30) we see that the solutions of the equations in Sections 2, 3, and 4 all converge to the same function both pointwise and in $\mathrm{L}^{2}$.

Received: April 2011. Revised: May 2011.

\section{References}

[1] Burton, T. A., Examples of Lyapunov functionals for non-differentiated equations, Proc. First World Congress of Nonlinear analysts, 1992. V. Lakshmikantham, ed., Walter de Gruyter, New York, (1996) 1203-1214.

[2] Burton, T. A., Boundedness and periodicity in integral and integro-differential equations, Diff. Eq. Dynamical Systems 1(1993) 161-172.

[3] Burton, T. A., Volterra Integral and Differential Equations, Elsevier, Amsterdam, 2005

[4] Burton, T. A., Integral equations, periodicity, and fixed points, Fixed Point Theory 9 (2008) $47-65$.

[5] Burton, T. A., Liapunov Functionals for Integral Equations, Trafford, Victoria, B. C., Canada, 2008. (www.trafford.com/08-1365)

[6] Burton, T. A., Liapunov functionals, convex kernels, and strategy, Nonlinear Dynamics and Systems Theory 10(4)(2010) 325-337.

[7] Burton, T. A., Six integral equations and a flexible Liapunov functional, Trudy Instituta Matematiki i Mekhaniki UrO RAN 16(5)(2010) 241-252.

[8] Burton, T. A. and Dwiggins, D. P., Resolvents, integral equations, limit sets, Mathematica Bohemica 135(2010) 337-354. 
[9] Burton, T. A. and Haddock, John R., Qualitative properties of solutions of integral equations, Nonlinear Analysis $\mathbf{7 1}$ (2009) 5712-5723.

[10] Levin, J. J., The asymptotic behavior of a Volterra equation, Proc. Amer. Math. Soc. 14(1963) $434-451$.

[11] Levin, J. J., The qualitative behavior of a nonlinear Volterra equation, Proc. Amer. Math. Soc. 16 (1965), 711-718.

[12] Levin, J. J., A nonlinear Volterra equation not of convolution type, J. Differential Equations 4 (1968), 176-186.

[13] Levin, J. J. and Nohel, J. A., Note on a nonlinear Volterra equation, Proc. Amer. Math. Soc. 14 (1963), 924-929.

[14] Londen, Stig-Olof., On the solutions of a nonlinear Volterra equation, J. Math. Anal. Appl. 39 (1972), 564-573.

[15] Miller, Richard K., Nonlinear Volterra Integral Equations, Benjamin, New York, 1971.

[16] Schaefer, H., Über die Methode der a priori Schranken, Math. Ann. 129(1955), 415-416.

[17] Volterra, V., Sur la théorie mathématique des phénomès héréditaires, J. Math. Pur. Appl. 7 (1928) 249-298.

[18] Yoshizawa T., Stability Theory by Liapunov's Second Method, Math. Soc. Japan, Tokyo, 1966.

[19] Zhang, B., Boundedness and global attractivity of solutions for a system of nonlinear integral equations, Cubo: A Mathematical Journal 11 (2009) 41-53.

[20] Zhang, B., Liapunov functionals and periodicity in a system of nonlinear integral equations, Electronic Journal of Qualitative Theory of Differential Equations, Spec. Ed. I, 2009 No. 1, $1-15$. 